\title{
Phonatory Onset and Vibratory Characteristics Based on Phonatory Type Using 2D Kymography and High Speed Videolaryngoscopy in Normal Speakers
}

\author{
Seong Hee Choi ${ }^{\mathrm{a}, \mathrm{b}}$, Min Sik Joo ${ }^{\mathrm{c}}$, Hye- Rim Chae ${ }^{\mathrm{c}}$, Chul-Hee Choi ${ }^{\mathrm{a}, \mathrm{b}}$ \\ ${ }^{a}$ Department of Audiology and Speech-Language Pathology, College of Bio and Medical Sciences, Daegu Catholic University, Gyeongsan, Korea \\ ${ }^{b}$ Research Institute of Biomimetic Sensory Control and Catholic Hearing Voice Speech Center, Daegu Catholic University, Gyeongsan, Korea \\ 'Department of Audiology and Speech-Language Pathology, The Graduate School of Health and Medical Science, Daegu Catholic University, \\ Gyeongsan, Korea
}

\author{
Correspondence: Chul-Hee Choi, $\mathrm{PhD}$ \\ Department of Audiology and Speech-Language \\ Pathology, Daegu Catholic University, 13-13 \\ Hayang-ro, Hayang-eup, Gyeongsan 38430, Korea \\ Tel: +82-53-850-2541 \\ Fax: +82-53-359-0780 \\ E-mail: cchoi@cu.ac.kr
}

Received: October 4, 2019

Revised: November 28, 2019

Accepted: December 10, 2019

This work is supported by 2019 research grant of Daegu Catholic University.

\begin{abstract}
Objectives: Phonation onset provides an important clinical cue in diagnosing pathologic voice conditions. The aim of this current study was to explore the vocal fold kinematics during three different types (breathy, normal, hard glottal attack) of voice onset with videokymography and high-speed digital imaging. In addition, to elucidate how phonation onset affects vocal fold vibration in stable sections, quantitative parameters were measured in stable vocal fold vibrations. Methods: High speed digital imaging (HSDI) was obtained from 35 normal young adults with different phonatory onset types (normal, breathy, hard glottal attack). Pre and phonatory onset data were investigated qualitatively with digital kymography (DKG); MinArea, MaxArea, MinOpen, MaxOpen, and speed quotient (SQ), were quantitatively measured by glottal area waveform analysis using Kay's Image Processing Software; and closed quotient (CQ) and open quotient (OQ) were obtained by 2D DKG using multifunctional examination system. Results: Significantly higher MinArea were revealed in breathy phonation $(p<.001)$ with no gender effect. With respect to MaxArea, both gender and phonation type effect was observed $(p<.001)$. Significantly larger MaxArea was found in a breathy phonation and the male group. Similar to MinArea, breathy phonation was significantly widest in MinOpen than other phonation types $(p<.001)$. While there were no significant differences in MaxOpen based on phonation types, the MaxOpen of males was significantly wider than that of females $(p<.001)$. SQ was also significantly higher in breathy phonation than normal and hard phonation. On the other hand, $\mathrm{OQ}$ and CQ showed significant effect on phonatory type without gender effect. Conclusion: The onset of vocalization was easily observed through HSDI and DKG, and there were notable differences in pre-phonatory and vibratory onset according to phonatory onset type. In addition, voice onset gesture also affected vocal fold vibration in the steadystate portion.
\end{abstract}

Keywords: Phonation onset, GAW, High speed digital imaging, 2D kymography, Phonation type, Normal
발성 개시는 음성의 중요한 특징 중 하나이며, 성대가 서로 중앙 에서 만나기 위해 내전 시 진동 특성은 음성장애의 원인이 되거나 다른 신경학적 기능부전의 지표로서 임상적으로 매우 중요하다. 성대가 진동하는 동안 폐쇄방법과 형태는 음질에 매우 중요한 영향
을 미치며, 진동의 양상에 따라 음질이 달라진다. 청지각적으로는 갑작스러운 혹은 강한 성대접촉, 정상 및 기식적인 혹은 부드러운 발성 시작으로 구분할 수 있으며, 이러한 발성 개시 특성은 호기류 와 성대 내전과 관련된 내측 압축(medial compression)의 정도에 
따라 다르게 나타난다(Koike et al., 1967). 발성 시작 시 강한 성대접 촉은 성대의 지나친 과내전으로 인해 성대 점막에 불필요한 충격을 증가시키고 습관적인 강한 성대접촉은 양성성대질환의 원인이 된 다(Andrade et al., 2000). 이와는 반대로 부드러운 발성 개시는 소 리를 산출하기 전에 성대를 꽉 조여서 폐쇄시키는 대신 호기 시작 후 성대를 천천히 내전시켜 발성하는 것으로 발성 시 성대의 충격 을 최소화할 수 있다. 기식적인 부드러운 발성 시작은 하품-한숨법 과 같이 과기능적 음성장애 환자의 음성치료법으로 사용되는데, 이러한 발성 개시 유형에 따른 성대진동의 기능적 평가는 음성장애 발생 기전을 이해하거나음성치료기법을 이해하는 데 유용하다.

발성 개시 움직임은 성대가 처음으로 내전되기 시작할 때부터 안 정된 발성을 하기까지 움직임을 말하는데(Chen, Woo, \& Murry, 2018), Titze (2000)는 발성 개시 움직임을 관찰하는 것이 정상적인 성 대 진동과 비정상적인 성대진동을 구분하는 데 중요하다고 하였다.

발성 개시는 성대가 거의 내전 될 때부터 막 성대진동이 눈에 띨 때까지 기간인 발성 전 지연(pre-phonatory delay, $\mathrm{PPD}$ ) 단계와 성 대진동이 처음 시작될 때부터 안정하게 진동할 때까지의 시간인 안 정상태지연(steady state delay, SSD)로 나눌 수 있다(Chen et al., 2018). PPD는 적절한 긴장과 내전, 공기역학적 힘의 조절과 관련된 단계이며, $\mathrm{SSD}$ 는 성대진동의 시작과 소리 생성과 관련이 있는 단계 인데(Watson, Baken, \& Roark, 2016), 발성이 시작될 때 성대진동 은 비주기성이 많이 관찰된다(Choi, Oh, \& Choi, 2015).

Werner-Kukuk과 von Leden (1970)은 초고속 영화촬영술(high speed cinematography)를 사용하여 발성 개시 유형에 따른 성대진 동 특성을 살펴 보았는데, 기식적인 발성 시작은 최대 진폭에 이르 기까지 점차적으로 성대진폭이 증가한 반면, 강한 성대접촉의 발성 개시는 성대진폭이 빠르게 증가하였다고 보고하였다. 또한, 성대를 강하게 접촉하여 발성을 시작할 때 가성대가 많이 움직였으나, 기 식적인 발성 개시에서는 가성대가 거의 움직이지 않는다고 하였다.

Cooke, Ludlow, Hallett와 Selbie (1997)의 연구에서는 연성 후두 내시경을 사용하여 양쪽 성대 돌기 간의 거리에 따라 성대 내전의 정도를 측정하였다. 발성 개시와 관련된 성대 내전 특성을 조사한 결과, 성대 내전의 기간은 기식적인 발성 시작 시 가장 길고 강한 성 대접촉으로 소리를 내기 시작할 때 가장 짧았다. 최근 Iwahashi, Ogawa, Hosokawa, Kato와 Inohara (2017)는 초고속 디지털 후두 내시경을 사용하여 20 명의 정상 화자를 대상으로 허밍이 발성 전 성대 움직임에 미치는 영향을 조사하였는데 강한 발성은 순간적인 발성 전 폐쇄를 보였으나, 허밍은 발성 전 단계(pre-phonatory phase) 에 걸쳐 성대 내전 시 속도가 감소하여 부드러운 발성 시작을 촉진 하였다고 하였다. 이러한 발성 개시 유형에 관한 선행연구들은 주
로 발성 개시의 진동 특성에 국한된 것으로 발성 시작의 특성이 성 대의 안정된 구간의 성대진동에 어떠한 영향을 미치는지 밝혀지지 않았다.

현재까지 후두비디오스트로보스코피는 표준 검사로서 음성장 애 진단을 목적으로 임상에서 주로 사용되고 있지만, 여러 진동주 기에 걸쳐 모아진 영상으로 만들어졌기 때문에 성대 왕복 움직임이 거의 주기적이거나 주기적인 성대진동만을 관찰하는 데 용이하며, 안정된 주파수에서 3-5초 이상 발성하기 어려운 경우나 비주기적이 거나 불규칙적인 성대진동을 하는 경우는 분석하는 데 문제가 있 다. 한편, 발성 개시는 전통적 검사방법인 후두비디오스트로보스 코피로는 검사가 불가능한데, 후두비디오스트로보스코피의 촬영 원리는 모음 발성 시 기본주파수를 인식한 후 이보다 느린 속도로 광원을 발광하여 실제 진동보다 느린 영상을 구현하기 때문에 실제 발성 개시의 부분을 관찰할 수 없다. 또한, 전기성문파형검사(electroglottography, EGG)는 성대접촉 영역에 비례하여 원래의 시작 진동 신호와 거의 관련이 없는 복잡한 신호를 제공하므로 발성 개 시의 성대진동 특성을 관찰하기 어렵다. 이러한 후두비디오스트로 보스코프의 단점을 보완하기 위하여 최근 초고속비디오후두영상 이나 비디오 카이모그래피(video kymography, VKG)와 같은 영상 기술이 사용되고 있다(Patel, Dailey, \& Bless, 2008; Švec \& Schutte, 1996).

초고속비디오후두내시경검사는 초당 10,000 정도 프레임까지 녹화할 수 있기 때문에 실제 성대진동보다 더 높은 프레임률로 녹 화하므로 한 주기 동안 성대의 진동 양상을 직접 관찰할 수 있다. 따라서, 성대진동의 개시나 종료 부분도 관찰이 가능하며 발성 개 시와 같이 심한 비주기적인 성대 움직임도 효과적으로 관찰할 수 있는 장점이 있다(Choi \& Choi, 2012). 또한, 비디오 초고속 카메라 로 녹화된 영상을 후처리하여 성문폭파형(glottal width waveform), 성문면적파형(glottal area waveform, GAW) 및 디지털 카이모그래 피(digital kymography, DKG) 등을 분석할 수 있다. 성문면적파형 은 시간에 따른 상대적인 성문 공간을 분석하는 것으로 후두 영상 이미지를 통해 성대진동의 특성을 정량적으로 측정할 수 있다. $\mathrm{DKG}$ 를 통해 추출된 카이모그램은 선택된 하나의 수평 라인인 성 문의 가로축에서 성대 움직임을 보여주며, 주기성, 좌우 비대칭, 외 측 및 내측 가장자리 경계 모양 등 다양한 성대의 기능적 평가를 할 수 있으므로(Švec, Šram, \& Schutte, 2007; Wittenberg, Tigges, Mergell, \& Eysholdt, 2000), 발성 개시 시 왼쪽과 오른쪽 성대의 진동 특성 을 보기에 용이하다. 또한 $\mathrm{DKG}$ 를 통해 성문 윤곽을 검출하고, 성 대의 가장자리를 분할하여 성대가 열리고 닫히는 과정을 성문면적 파형을 통해 나타낼 수 있다. 하지만, DKG나 초고속비디오후두내 
시경 검사는 촬영시간이 짧고 녹화된 이미지의 처리 과정이 10-30 분 정도 소요되기 때문에 녹화시간이 많이 걸리고 각 검사마다 대 용량 저장데이터를 필요로 하는 단점이 있다.

한편, 최근에는 초고속비디오후두내시경검사를 기반으로 하여 후두경과 카이모그래픽 이미지를 동시에 관찰할 수 있는 $2 \mathrm{D}$ 평면 카이모그래피(two-dimensional scanning digital kymography)가 개발되었다(Kang et al., 2017; Wang et al., 2016a, 2016b). 이 방법은 기능적 이미지 기법으로서 성대 전체의 동적 움직임을 분석할 수 있는데 VKG는 전체 성대 중 특별한 한 선에서 성대 움직임만을 관 찰하기 때문에 성대 전체 움직임을 관찰하는 것이 불가능하지만, $2 \mathrm{D} \mathrm{VKG}$ 는 초당 32,400 선과 25 프레임으로 성대 전체 움직임의 변 화를 관찰할 수 있다(Kang et al., 2017). 따라서, $2 \mathrm{D} \mathrm{DKG}$ 는 다양한 발성 유형에 따라 성대의 한 부분 만의 진동 특성을 보여주는 것이 아니라 성대 전체 움직임을 보여 주므로 성대 움직임의 시공간적 정보를 좀 더 정확하게 제공해 줄 수 있을 것이다. 또한, 후두 영상 분석과 관련하여 성문면적파형 $(\mathrm{GAW})$ 은 시간에 따른 상대적인 성 문 공간을 분석하는 것으로 후두 영상이미지를 통해 성대 진동의 특성을 정량적으로 측정할 수 있다. 따라서, 본 연구는 정상 화자를 대상으로 DKG, $2 \mathrm{D} \mathrm{DKG}$, 성문면적파형 분석을 통해 발성 개시 유 형(기식적, 정상, 강한 성대접촉)에 따른 발성 개시 특성을 살펴 보 고, 아울러 발성 개시 특성이 안정된 구간의 성대 움직임에 어떠한 영향을 미치는 지 살펴보고자 한다.

\section{연구방법}

\section{연구대상}

본 연구의 대상자는 이비인후과 의사에 의해 후두내시경 소견상 기능적 문제가 없는 자를 대상으로 하였다. 또한, 설문지를 통해 과 거나 현재에 흡연을 하지 않으며, 음성 훈련을 받지 않았고, 음성에 관련한 질환, 후인두 관련 수술, 후인두역류 등의 문제가 없는 자들 을 대상으로 하였다. 참여자는 총 35 명(남 15 명, $22.33 \pm 1.80$ 세; 여 20 명, $21.05 \pm 0.83$ 세)으로 평균 연령은 22 세였다.

\section{검사 도구 및 실험 절차}

Kang 등(2017)의 선행연구에서 사용하였던 다기능 후두성능검 사시스템(multifunctional examination system; USC-700MF, UMedical, Korea)을 사용하여 실시간 성대진동 검사를 실시하였다 (Figure 1). $300 \mathrm{~W}$ xenon 광원과 직경 $7 \mathrm{~mm}, 70^{\circ}$ 경성 내시경(8700 CKA, Karl Storz, Tuttlingen, Germany)를 사용하여 성대 영상을 촬영하였다. 영상은 $208 \times 304$ 해상도에서 초당 1,500 장을 저장하
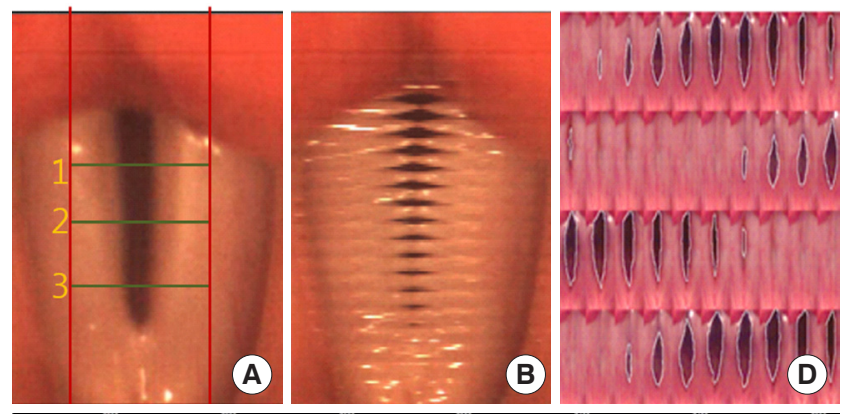

line1

line2

line3

Figure 1. Multifunctional examination system including high-speed videoendoscopy (A), 2D DKG (B), DKG (C), and multi-frame videostroboscopy. Glottal area waveform analysis using Kay's Image Processing Software (D). $D K G=$ digital kymography.

였으며, 10초 동안 촬영하였다. 촬영된 HSV 영상을 로딩시킨 후 $\mathrm{DKG}$ 와 $2 \mathrm{D} \mathrm{DKG}$ 를 구현하였다. 단일픽셀 라인은 이미지 분석에 어려움이 있으며 2픽셀 라인 스캐닝이 정량적 평가에 유용하다는 Kang 등(2017)의 연구에 따라 $2 \mathrm{D} \mathrm{DKG}$ 는 2픽셀 라인 스캐닝을 사 용하였으며, DKG는 3픽셀 라인 스캐닝을 사용하여 이미지를 변환 하였다.

참여자들은 검사 전 정상, 강한 성대접촉, 기식적 발성 개시의 세 가지 발성 유형별 훈련을 실시하였으며, 세 가지 발성 개시 형태를 사용하는 동안 음도의 변화를 줄이기 위해 Real Time-Pitch (model 5121, KayPENTAX, Lincoln Park, NJ, USA) 프로그램을 이용하 여 훈련을 하였다. 성대진동검사 전 발성 개시를 모델링해주고 검 사는 /i/ 모음으로 정상, 부드러운, 강한 성대접촉 순으로 발성하도 록 하였다. 정상 발성 개시는 평상 시 편안한 음높이와 강도에서 /i/ 소리를 내도록 하였다. 한편, 기식적인 발성 개시는 먼저 $/ \mathrm{h} /$ 을 산출 하게 한 후/h/ 소리를 과장되게 기식화한 후 부드럽게 /i/ 모음을 이 어서 소리 내도록 하였으며, 강한 성대접촉은 발성 시작 시 성대를 빠르고 강하게 닫아서 /i/ 소리를 내도록 유도하였다. 각각의 참여 자들은 세 가지 발성 형태를 사용하는 동안 음도의 변화를 \pm 20 $\mathrm{Hz}$ 범위 내에서 발성할 수 있도록 충분히 훈련하였다.

\section{분석방법}

GAW분석

초고속디지털영상법을 이용해 성문면적파형(GAW)을 정량적 
으로 분석하기 위하여 KIPS (Kay's Image Processing Software; model 9181, KayPENTAX) 를 이용하였다. 전체 성문 영역 파형을 측정하기 위하여 발성 개시 유형에 따른 성대진동 특성의 양적 분 석을 위해 Ulead VideoStudio 9 (Corel corp., Ottawa, ON, Cana$\mathrm{da}$ )를 이용하여 영상을 편집하였고, 영상의 편집 시작점은 성대가 완전히 외전된 상태이며 편집 종료점은 규칙적인 성대진동이 25-30 주기 사이로 나타나는 지점으로 정하였다. 이미지는 .avi 파일형식 으로 저장하였으며, 해상도는 $640 \times 480$ 으로 하였다. 성문면적파 형 분석은 성대 가장자리를 추적하여 성대 면적의 동적 변화에 대 한 정보를 제공하는데, 본 연구에서는 GAW 분석을 하기 위해 분 석하고자 하는 영역을 지정한 후, Set frame advance는 1 , Number of rows는 4, Number of image per row는 10으로 설정하여 디지털 화 된 40 개의 정지화면 즉, 몽타주(Montage)를 추출하였다. 추출한 몽타주에서 영역 탐지(edge detection) 알고리즘을 통해 윤곽을 추 출하여(Figure $1 \mathrm{D})$, 명암의 차에 따라 성문 공간이 픽셀 숫자로 자 동 측정되었으며, 최소성문면적(MinArea), 최대성문면적(MaxArea), 최소개방너비(MinOpen), 최대개방너비(MaxOpen), 최소성문 면적비율(MinARate), 최대성문면적비율(MaxARate), 속도율(SQ) 이 자동 계산되었다. GAW의 정량적 분석은 각 대상자의 세 가지 발성 개시 유형(정상, 기식적인, 강한 성대접촉 발성)에 따라 총 105 개의 GAW 영상이미지를 분석 하였으며, 분석은 발성개시 1 초 후 발성이 안정된 3주기 구간을 평균하여 측정하였다(Patel et al., 2012; Yamauchi et al., 2015). 각 발성 개시 유형에 따라 MinArea, MaxArea, MinOpen, MaxOpen, MinARate, MaxARate, SQ를 측정하
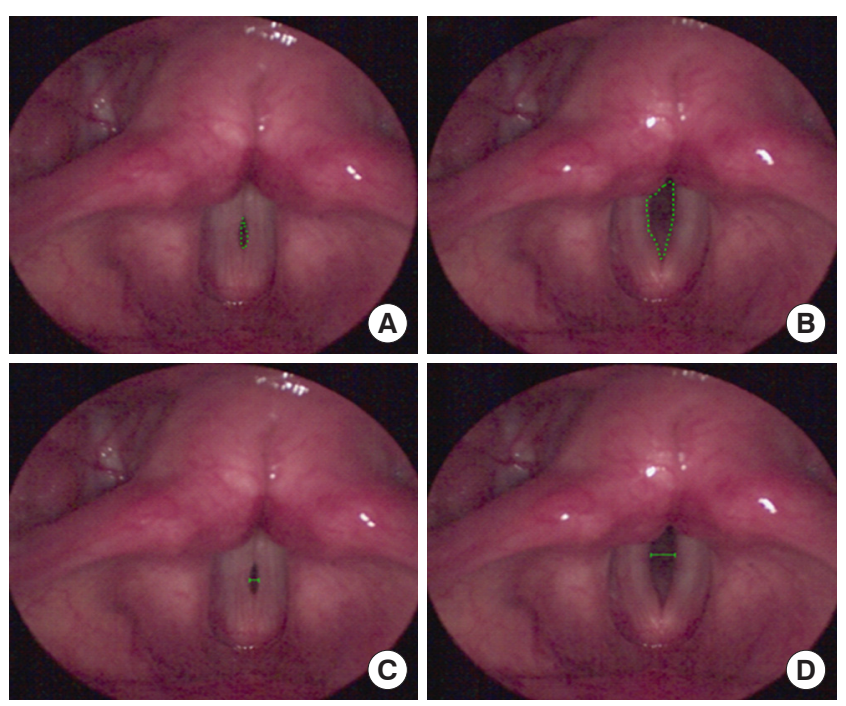

Figure 2. Glottal area waveform (GAW) analysis measures using Kay's Image Processing Software: (A) MinArea, (B) MaxArea, (C) MinOpen, and (D) MaxOpen.
였다(Figure 2). MinArea는 발성 동안 가장 좁은 성문면적이며, MaxArea는 발성동안 가장 넓은 성문면적을 말한다. MinOpen은 발성동안 성문의 중간지점에서 최소개방너비를 말하며, MaxOpen 은 발성동안 성문의 중간지점에서 최대개방너비를 의미한다. MinARate는 성문공간에서 최소성문면적 변화의 비율을 의미하며, MaxARate는 성문공간에서 최대성문면적 변화의 비율을 말한다. SQ는 성문개방위상 시간을 성문폐쇄위상 시간으로 나눈 비율을 말한다.

한편, 디지털카이모그래피를 통해 발성 개시 유형에 따른 발성 시작 특성을 질적으로 분석하였다. 평면 스캔 디지털카이모그래피 (2D DKG) 영상에서 추출된 이미지는 분석 시 이미지를 확대하였 을 때도 변함없는 형태와 색을 유지하기 위해 Illustrator 프로그램 (Adobe Systems Inc., San Jose, CA, USA)을 사용하여 벡터화(vectorize)하였다. 그 다음 성대진동의 정량적 분석을 위해 Image J 소 프트웨어(NIH, Bethesda, MD, USA)를 사용하여 8 bit grayscale로 변환하여 분석하였으며(Kang et al., 2017), 개방지수(open quotient, $\mathrm{OQ}$ ) 및 폐쇄지수(closed quotient, CQ)값을 구하였다(Figure 3). $\mathrm{OQ}$ 는 성대진동 주기에서 성문이 열려 있는 동안의 시간의 비율로, 성문의 불완전한 폐쇄 시에 증가하게 되며, $\mathrm{CQ}$ 는 성대진동 주기에 서 성문이 닫혀 있는 동안의 시간의 비율로 계산하였다(Kim, 2017).

\section{통계 분석}

통계 처리는 SPSS version 19.0를 이용하여 발성 유형과 성별에 따라 성별(집단 간), 발성 유형(집단 내)요인으로 이원혼합분산분

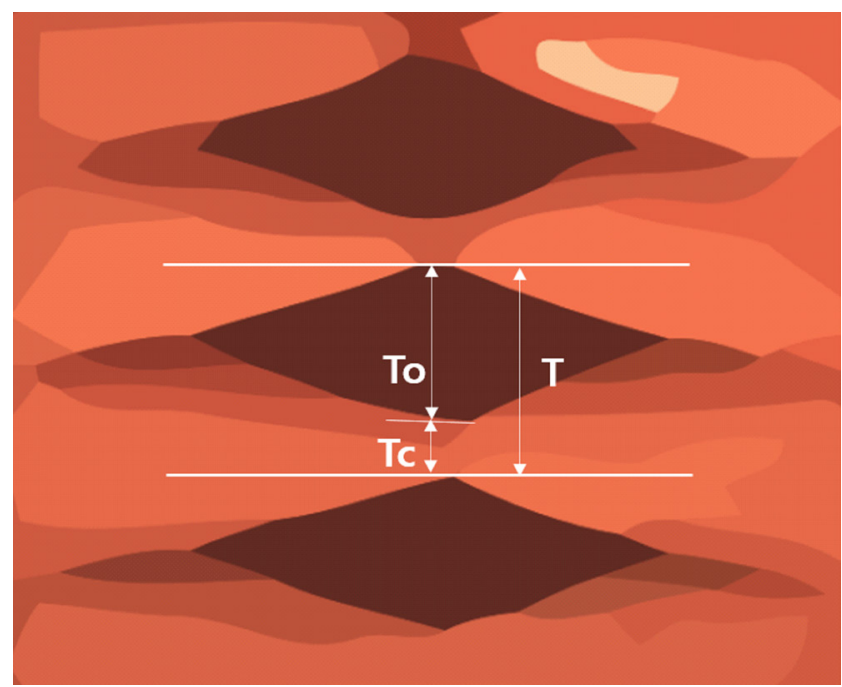

Figure 3. Quantitative analysis of glottal area waveform in two-dimensional scanning digital kymography (2D DKG). $\mathrm{T}$ is the length of a single vibratory cycle, To is the length fo the open phase, and $T_{c}$ is the length of the closed phase (open quotient $=\mathrm{T}_{0} / \mathrm{T}$, closed quotient $=\mathrm{Tc} / \mathrm{T}$ ). 
Seong Hee Choi, et al. • Phonatory Onset and Vibratory Characteristics of Phonatory Types

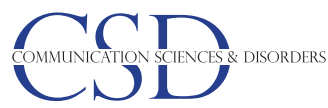

석(two-way Mixed ANOVA)을 통해 유의성을 검증하였다. Mauchly의 구형성 검정에 의해 구형성이 가정된 경우, 개체 내 효과 검정 의 구형성 가정값을 사용하였고, 구형성 가정이 되지 않은 경우는 Greenhouse-Geisser로 수정한 값을 사용하였으며, 유의 수준은 $95 \%$ 이였다.

\section{연구결과}

\section{발성 개시 유형에 따른 발성 개시의 DKG, 2D DKG 분석}

Figures 4 와 5 는 각각 발성 개시 유형에 따른 모음/i/발성의 DKG, $2 \mathrm{D} \mathrm{DKG}$ 이미지이다. $\mathrm{DKG}$ 를 이용하여 발성 개시 특성을 살펴본 결과, 강한 성대접촉으로 발성을 시작했을 때 성대 내전 후 갑작스 러운 성대접촉을 보였으며, 내전 후 긴 정지상태를 보였다. 또한, 진
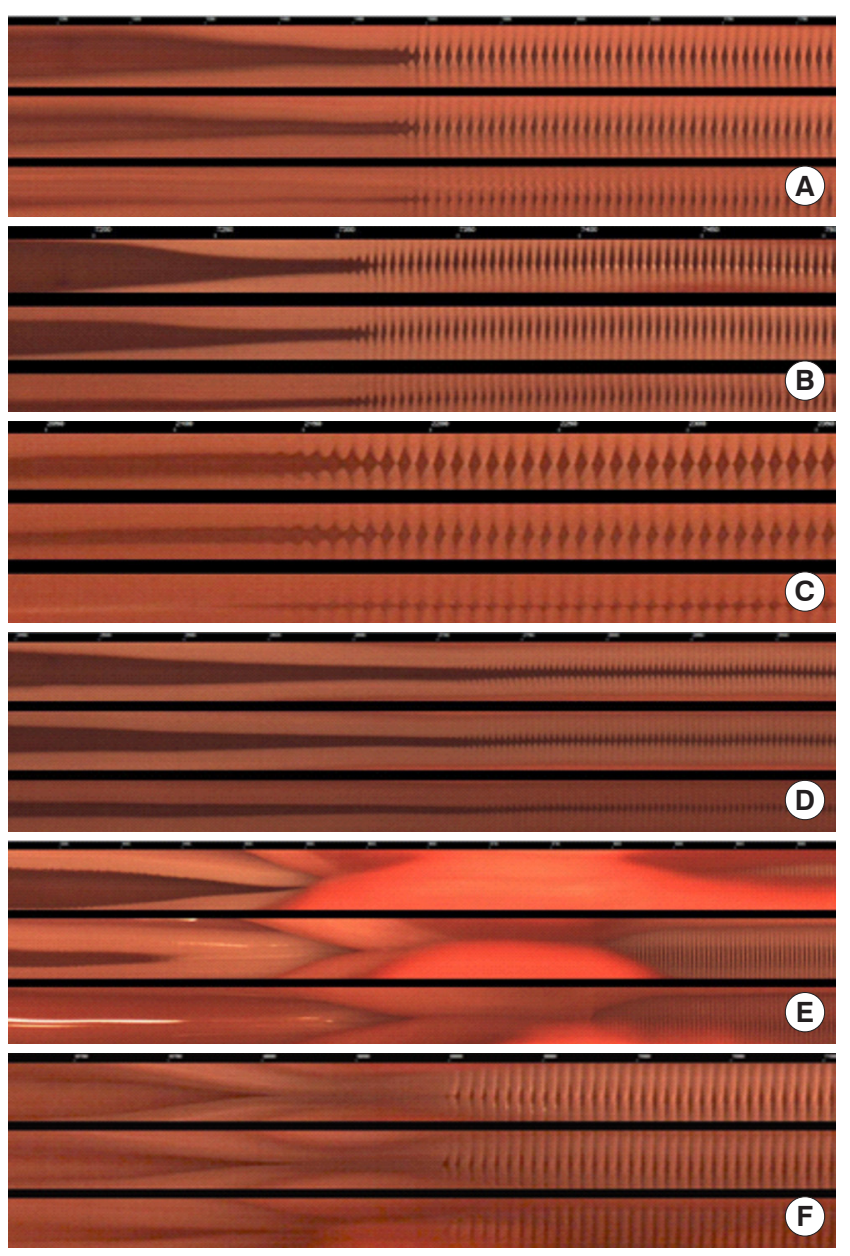

Figure 4. Qualitative analysis in digital kymography (DKG) of pre-phonatory and phonatory onset from top to bottom with 3 scan line: (A) normal in a male, (B) normal in a female, (C) breathy in a male, (D) breathy in a female, (E) hard glottal attack in a male with complete closure of ventricular folds, and (F) hard glottal attack with incomplete closure of ventricular folds in a female.
성대의 접촉 동안 가성대 수축으로 인해 진성대가 가리워지는 특 성을 보였다. 특히, DKG상에서 가성대 수축은 대부분 완전한 가성 대 접촉으로 진성대를 가리는 경우가 대부분이었으며, 대상자 중 6 명만 불완전한 가성대 접촉을 보였다(Figure 4). 한편, 기식적인 발 성 개시는 발성 전 지연 단계에서 성대접촉이 없었으며, 가성대 부 분이 발성 시 개입하지 않았고 발성 전 점진적으로 성대접촉이 이 루어지는 양상을 보였다. 정상적인 발성 개시는 성대접촉 후에도 비 주기적인 발성이 일시적으로 반복되다가 주기적 발성 패턴으로 전 환되는 것이 관찰되었다.

발성 개시 시 $\mathrm{DKG}$ 분석 결과, 정상적인 발성 개시와 기식적인 발 성 개시는 약간의 왼쪽-오른쪽 성대의 비대칭성을 보였으나, 강한 성대접촉 발성 개시는 가성대가 진성대를 가리지 않는 경우는 왼 쪽-오른쪽 성대의 대칭적 패턴을 보였다. 또한, 발성 개시 후 성대의 안정적인 발성 부분에 영향을 주었는데, $2 \mathrm{D} \mathrm{DKG}$ 영상에서 보듯이 강한 성대접촉은 여전히 폐쇄기가 더 길고 개방기가 더 짧은 형태 의 진동 패턴을 보였으며, 기식적인 발성 개시는 폐쇄기보다 개방기 가 더 긴 형태의 발성 패턴을 보였다. 이러한 특성은 발성 개시가 안 정된 구간의 성대진동에도 동일한 패턴을 보여 발성 개시 특성이 발성 안정기에도 영향을 주어 전반적인 음질에 영향을 줌을 알 수 있다(Figure 5).

\section{발성 유형과 성별에 따른 성문면적파형(GAW) 측정치 비교}

발성 유형과 성별에 따른 MinArea, MaxArea, MinOpen, MaxOpen, MinARate, MaxARate, SQ의 평균과 표준편차는 Table 1과 같다.

MinArea의 경우, 혼합 분산 분석 결과, 발성 개시 유형과 성별 간 의 상호작용은 유의하지 않았고, 남성과 여성 간에는 유의한 차이 를 보이지 않았으며, 발성 유형 간 MinArea는 통계적으로 유의한 차이를 보였다 $\left(F_{(1,33.004)}=19.704, p<.001\right)$. 대응별 비교 결과, 정상 발 성 개시군 vs. 부드러운 발성개시군 $(p<.001)$, 강한 성문접촉 발성개 시군 vs. 부드러운 발성개시군 $(p<.001)$ 간에 유의한차이를 보였다.

MaxArea는 발성 개시 유형과 성별 간의 상호작용은 유의하지 않았고, 발성 개시 유형 $\left(F_{(2,66)}=16.668, p<.001\right)$ 과 성별 $\left(F_{(1,33)}=45.247\right.$, $p<.001)$ 은 유의한차이를 보였다. 대응별 비교 결과, 정상 발성개시 군과 강한 성문접촉 발성개시군 $(p=.005)$, 정상 발성개시군과 기식 적인 발성개시군 $(p<.001)$, 강한 성문접촉 발성개시군과 기식적인 발성개시군 $(p=.004)$ 모두에서 유의한 차이를 보였다.

MinOpen의 측정치의 경우, 발성 개시 유형과 성별 간의 상호작 용은 유의하지 않았고, 성별 간에 유의한 차이를 보이지 않았으며, 발성 개시 유형에 따라 통계적으로 유의한 차이를 보였다. 즉, 발성 

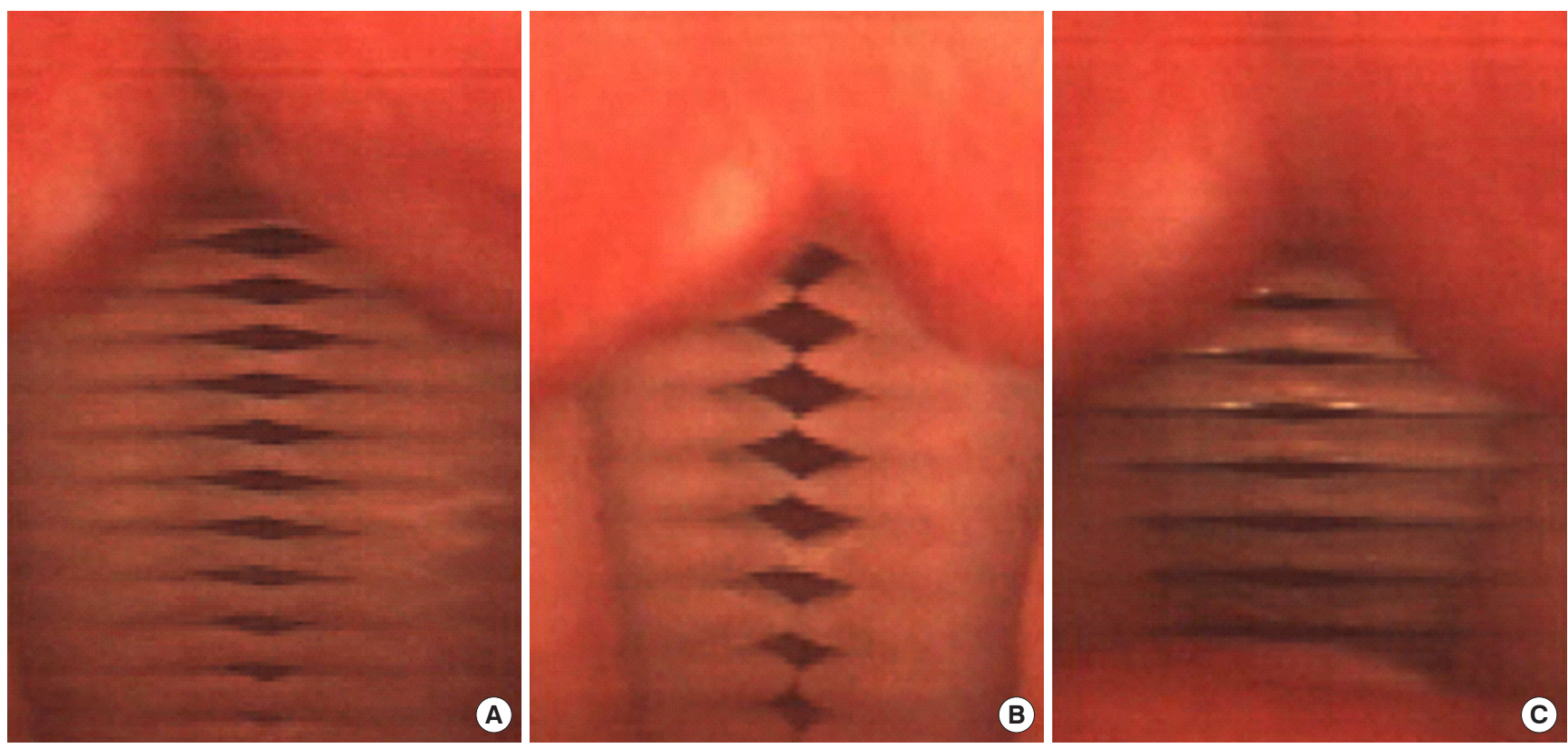

Figure 5. Qualitative analysis of two-dimensional scanning digital kymography (2D DKG) based on phonatory onset type: (A) normal, (B) breathy, and (C) hard glottal attack.

개시 유형 간 MinOpen은 통계적으로 유의한 차이를 보였으며 $\left(F_{(1.018,33.591)}=40.638, p<.001\right)$, 발성 개시 유형 간 대응별 비교 결과, 정상 vs. 기식적인 발성개시군 $(p<.001)$, 강한 성대접촉 발성개시군 vs. 기식적인 발성개시군 $(p<.001)$ 간에 유의한차이를 보였다.

MaxOpen은 발성 개시 유형과 성별 간 상호작용은 유의한 차이 를 보이지 않았고, 성별 간에는 유의한차이를 보였으나 $\left(F_{(1,33)}=20.812\right.$, $p<.001$ ) 발성 유형 간에는 통계적으로 유의한차이를 보이지 않았다.

MinARate는 발성 개시 유형과 성별 간의 상호작용은 통계적으 로 유의한 차이를 보였다 $\left(F_{(1.621,53.489)}=3.751, p=.038\right)$. 남성과 여성 간에도 유의한 차이를 보였으며 $\left(F_{(1,33)}=23.155, p<.001\right)$, 발성 개시 유형 간에는 통계적으로 유의한 차이를 보였다 $\left(F_{(1.621,53.489)}=11.147\right.$, $p<.001)$. 대응별 비교 결과, 정상 vs. 강한 성대접촉 발성개시군 $(p<$ $.001)$, 강한 성대접촉 발성개시군 vs. 기식적인 발성개시군 $(p=.005)$ 간에 유의한 차이를 보였다.

$\mathrm{SQ}$ 는 발성 개시 유형과 성별 간의 상호작용도 유의하지 않았고 $\left(F_{(1.454,47985)}=3.539, p=.051\right)$, 성별 간에는 유의한 차이를 보이지 않 았으며, 발성 개시 유형 간 속도율은 통계적으로 유의한 차이를 보 였다 $\left(F_{(1.454,47.985)}=11.023, p<.001\right)$. 대응별 비교 결과, 정상 발성개시 군 vs. 강한 성대접촉 발성개시군 $(p<.001)$, 강한 성대접촉 발성개시 군 vs. 기식적인 발성개시군 간에 유의한 차이를 보였다 $(p<.001)$.

$\mathrm{CQ}$ 는 발성 개시 유형과 성별 간의 상호작용은 유의하지 않았고, 성별 간에도 유의한 차이를 보이지 않았으나(Figure 6), 발성 유형
간 $\mathrm{CQ}$ 는 통계적으로 유의한 차이를 보였다 $\left(F_{(1.454,47.985)}=283.306\right.$, $p=.000)$. 대응별 비교 결과, 정상 vs. 기식적인 발성개시군 $(p=.000)$, 정상 vs. 강한 성대접촉 발성개시군 $(p=.000)$, 강한 성대접촉 발성 개시군 vs. 기식적인 발성개시군 간에 유의한차이를 보였다 $(p=.000)$.

$\mathrm{OQ}$ 는 발성 유형과 성별 간 상호작용은 유의하지 않았고, 성별 간 에도 유의한 차이를 보이지 않았으나(Figure 7), 발성 유형 간 $\mathrm{OQ}$ 는 통계적으로 유의한 차이를 보였다 $\left(F_{(1.454,47.985)}=284.423, p=.000\right)$. 대응별 비교 결과, 정상 vs. 기식적인 발성개시군 $(p=.000)$, 정상 vs. 강한 성대접촉 발성개시군 $(p=.000)$, 강한 성대접촉 발성개시군 vs. 기식적인 발성개시군 간에 유의한 차이를 보였다 $(p=.000)$.

\section{논의 및 결론}

본 연구는 초고속 후두내시경과 $\mathrm{DKG}$ 를 사용하여 발성 개시 유 형에 따른 발성 전 및 발성 개시 특성을 살펴 보았으며, $2 \mathrm{D} \mathrm{DKG}$ 와 KIPS를 사용하여 안정된 발성 동안 발성 유형에 따른 GAW을 분 석하여 성대진동의 동적인 특징을 정량적으로 분석하였다.

정상적인 소리를 낼 때 일반적으로 성대는 $100-300 \mathrm{~Hz}$ 의 범위로 매우 빠르게 움직이는 데 이러한 성대 움직임을 육안으로 직접 관 찰하는 것은 진단뿐 아니라 성대의 기능적 특성을 조사하는 데 매 우 유용하다. 성대 진동의 직접적인 평가는 형태 및 기능적 평가가 모두 가능한 데 형태나 해부학적 평가는 후두비디오스트로보스코 
Table 1. GAW measures based on the phonatory type using KIPS and 2D DKG

\begin{tabular}{|c|c|c|c|c|}
\hline & Type & Male (N=15) & Female (N=20) & Total (N=35) \\
\hline \multirow[t]{3}{*}{ MinArea (pixel) } & Normal & $0(0)$ & $0(0.34)$ & $0(0.17)$ \\
\hline & Hard & $0(0)$ & $0(0)$ & $0(0)$ \\
\hline & Breathy & $2.27(2.04)$ & $2.41(2.27)$ & $2.34(2.16)$ \\
\hline \multirow[t]{3}{*}{ MaxArea (pixel) } & Normal & $1413.13(500.27)$ & 610.82 (277.62) & 1011.98 (388.95) \\
\hline & Hard & 1629.68 (580.71) & 681.12 (329.48) & $1155.40(455.10)$ \\
\hline & Breathy & 1817.60 (534.28) & 857.02 (409.15) & 1337.31 (471.72) \\
\hline \multirow[t]{3}{*}{ MinOpen (pixel) } & Normal & $0(0)$ & $0(0.34)$ & $0(0.17)$ \\
\hline & Hard & $0(0)$ & $0(0)$ & $0(0)$ \\
\hline & Breathy & $2.27(2.04)$ & $2.41(2.27)$ & $2.34(2.16)$ \\
\hline \multirow[t]{3}{*}{ MaxOpen (pixel) } & Normal & 25.74 (7.29) & $15.75(4.06)$ & $20.75(5.68)$ \\
\hline & Hard & $23.71(5.01)$ & 17.64 (5.59) & $20.68(5.30)$ \\
\hline & Breathy & $25.73(6.60)$ & 20.65 (7.12) & $23.19(6.86)$ \\
\hline \multirow[t]{3}{*}{ MaxARate } & Normal & 438.36 (167.30) & 231.34 (108.11) & 334.85 (137.71) \\
\hline & Hard & 595.64 (206.76) & 284.41 (120.28) & 440.03 (163.52) \\
\hline & Breathy & 491.74 (171.93) & 274.61 (105.70) & 383.18 (138.82) \\
\hline \multirow[t]{3}{*}{ MinARate } & Normal & -412.22 (133.56) & $-249.53(104.37)$ & -330.88 (118.97) \\
\hline & Hard & $-582.13(250.19)$ & -320.12 (127.89) & $-451.13(189.04)$ \\
\hline & Breathy & $-419.19(112.37)$ & -299.32 (99.73) & $-359.26(106.05)$ \\
\hline \multirow[t]{3}{*}{ SO } & Normal & $0.54(0.26)$ & $0.87(0.48)$ & $0.71(0.37)$ \\
\hline & Hard & $0.43(0.32)$ & $0.59(0.40)$ & $0.51(0.36)$ \\
\hline & Breathy & $0.73(0.35)$ & $0.77(0.30)$ & $0.75(0.33)$ \\
\hline \multirow[t]{3}{*}{$\mathrm{CO}$} & Normal & $0.48(0.07)$ & $0.47(0.07)$ & $0.47(0.07)$ \\
\hline & Hard & $0.60(0.10)$ & $0.60(0.07)$ & $0.60(0.08)$ \\
\hline & Breathy & $0.23(0.08)$ & $0.23(0.08)$ & $0.23(0.08)$ \\
\hline \multirow[t]{3}{*}{00} & Normal & $0.52(0.07)$ & $0.53(0.07)$ & $0.53(0.07)$ \\
\hline & Hard & $0.40(0.10)$ & $0.40(0.07)$ & $0.40(0.08)$ \\
\hline & Breathy & $0.77(0.08)$ & $0.77(0.08)$ & $0.77(0.08)$ \\
\hline
\end{tabular}

Values are presented as mean (SD).

GAW = glottal area waveform; KIPS=Kay's Image Processing Software; 2D DKG=two-dimensional scanning digital kymography; $\mathrm{SQ}=$ speed quotient; $\mathrm{CQ}=$ closed quotient; $00=$ open quotient.

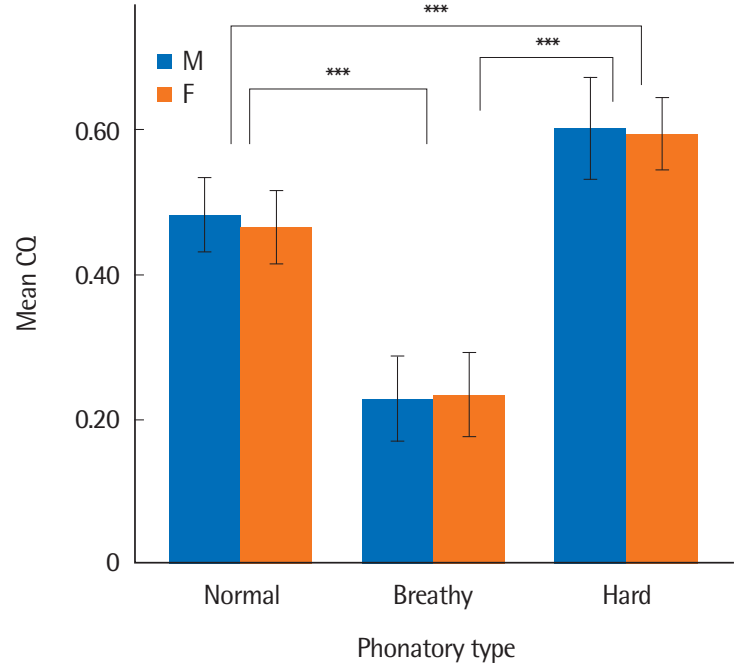

Figure 6. Mean closed quotient (CO) according to phonatory type. ${ }^{* * *} p>001$.



Figure 7. Mean open quotient (00) according to phonatory type. ${ }^{* * *} p>001$. 
피나 초고속비디오내시경검사를 사용할 수 있으며, 기능적 검사는 비디오 카이모그래피나 디지털 카이모그래피 등을 사용할 수 있 다. 특히, 초고속 디지털 후두내시경은 발성 개시부터 종료까지 성 대 전체의 진동 움직임에 걸쳐 주기간 진동 패턴을 관찰할 수 있는 유일한 이미지 기술이며 또한, 발성 동안 주기내 성대 움직임을 관 찰할 수 있으므로 발성 개시처럼 좀 더 일시적인 불규칙한 움직임 을 관찰하기에 적절하다(Deliyski et al., 2008). DKG는 시간에 따 른 각 성대 움직임의 정확한 협응을 기술할 수 있는 기능을 가지고 있으므로 발성 개시 시 성대의 움직임뿐 아니라 안정된 구간의 성 대 움직임에 대한 정보를 제공한다. 본 연구는 이러한 초고속 디지 털 후두내시경과 $\mathrm{DKG}$ 및 $2 \mathrm{D} \mathrm{DKG}$ 의 동시 실시간 구현을 통해 다 양한 발성 개시 유형에 따른 성대의 동적인 진동 특징을 살펴 보았다.

현재까지 발성 개시 특성의 연구를 보면, Orlikoff, Deliyski, Baken 과 Watson (2009)은 정상 화자 5명을 대상으로 전기성문파형검사 와 초고속 디지털 후두내시경을 이용하여 강한 성대접촉, 정상, 부 드러운 성대접촉 시 발성 개시 시간(진동이 처음 시작되는 부분부 터 성대가 처음으로 만나는 부분까지)을 측정하였는데, 기식성 발 성 개시가 가장 컸고, 강한 성대접촉은 음수의 값을 나타내었다.

Tigges, Wittenberg, Mergell과 Eysholdt (1999)도 카이모그래피를 이용하여 발성 개시 특성을 살펴 본 결과, 강한 성대접촉 발성이 정 상적인 발성 개시에 비해 발성 전 정지 시간이 더 길다고 보고하였 다. 또한, Wittenberg 등(2000)도 DKG를 사용하여 시지각적 분석 을 통해 다양한 발성 개시에 따른 발성 시작 패턴을 조사하였는데 강한 성대접촉의 발성 개시는 진성대가 가려지고 발성 전 가성대의 접촉과 함께 오랜 정지 시간을 보인 반면, 이와는 대조적으로 기식 적인 발성 시작 시 성문이 폐쇄되지 않고 가성대가 움직이지 않으 며 짧은 발성 단계를 보인다고 하여 본 연구와 비슷한 결과를 보였 다. 본 연구에서는 발성 개시 시간을 정량적으로 측정하지 않았으 나, 카이모그래피를 통해 살펴본 결과, 기식적인 발성 개시는 서서 히 성대진동이 처음 시작되어 성대가 접촉하는 패턴을 보였다. 반 면, 강한 성대접촉 발성 개시는 성대 전체가 먼저 내전과 함께 갑작 스럽게 접촉한 후 오랜 시간 동안 정지해 있다가 성대진동이 시작되 는 패턴을 보여 발성 개시 시 정상적인 발성 시작과 기식적인 발성 시작과는 다른 양상을 보였다. Chen 등(2018)의 연구에서도 6명의 내전형 연축성 발성장애 환자와 5 명의 근긴장성 발성장애 환자를 대상으로 디지털 카이모그래피를 사용하여 발성 개시 특성을 질적 으로 비교한 결과, 두 환자군 간 발성 개시 지연 시간에는 유의한차 이를 보이지 않았으나, 발성 개시 동안 성문 상부의 강한 수축을 보 여, 성대의 과기능이 모두 나타남을 보고하였다. 특히, 내전형 연축 성 발성장애 환자는 처음 성대진동 후에 갑작스러운 성대 내전이
나타난 후 안정된 발성까지 성대진동이 이루어진 반면, 이러한 성 대진동 일탈 패턴이 근긴장 발성장애 환자에게는 나타나지 않는다 고 하였다. 한편, 근긴장성 발성장애 환자군은 환자군 간 과기능 정 도가 차이가 있었으나, 환자군 중에는 성문상부의 수축 후 점진적 인 성대 외전과 성대진동의 개시가 관찰된다고 하였다. 본 연구에 서는 가성대가 진성대를 완전히 가린 경우는 가리워진 진성대 사 이로 이미 성대진동이 시작되고 있어 발성 개시 부분을 정확히 관 찰할 수 없었으나, 가성대가 완전히 진성대를 막지 않은 경우에서 는 완전한 진성대 접촉 후 성대 외전 없이 바로 성대진동이 시작되 어 Chen 등(2018)의 근긴장성 발성장애 환자와는 다른 양상을 보 였다. 이처럼 카이모그래피를 이용한 성대 개시 부분에 대한 질적 분석은 다양한 성대 질환을 감별하는 데 도움을 줄 수 있을 것이 다. 또한, 앞에서 언급한 바와 같이 발성 개시 유형에 따른 DKG 분 석 결과, 정상적인 발성 개시와 기식적인 발성 개시는 약간의 왼쪽오른쪽 성대의 비대칭성을 보였으나, 강한 성대접촉 발성 개시는 가 성대가 진성대를 가리지 않는 경우는 왼쪽-오른쪽 성대의 대칭적 패턴을 보였다. 따라서, 왼쪽-오른쪽 성대의 발성 개시의 차이는 발 성의 안정화되는데 걸리는 시간에 영향을 줄 수 있을 것이다.

한편, 본 연구에서는 GAW를 이용하여 안정된 발성 구간의 성대 진동 특성을 분석하였는데, MinArea 측정치를 비교했을 때 발성 개시 유형 간 차이를 보였으며, 정상 발성개시군-기식적인 발성개시 군, 강한 성문접촉 발성개시군-기식적인 발성개시군 간에 유의한 차 이를 보였다. Figure 8과 같이 강한 성대접촉 발성개시군은 모든 대 상자에서 내전 시 완전한 성문폐쇄를 보였으나, 부드러운 발성개시 군에는 완전한 폐쇄가 아닌 점막 문만 폐쇄되고 연골 성문은 개방 되는 모습을 보였으며, 남성이 여성에 비해 유의하게 높게 나타났다.

MaxArea 측정치를 비교하였을 때 기식적인 발성 개시가 가장 높았으며, 강한 성대접촉 발성, 정상 발성 순이었으며, 남성이 여성 에 비해 유의하게 높았다. 이러한 차이는 강한 성대접촉의 경우 정 상 발성보다 더 강한 힘으로 성대를 접촉하기 때문에 성대가 진동 하는 진폭의 증가로 인해 정상에 비해 더 넓은 면적으로 진동하였 다고 유추할 수 있다. 즉, 부드러운 발성 개시의 경우 완전한 폐쇄가 이루어지지 않고 많은 호기류로 성문이 더 넓게 개방이 되기 때문 에 오히려 강한 성문접촉 발성보다 더 넓은 성문면적을 차지했다고 볼수있겠다.

MinOpen 측정치의 경우 MinArea와 마찬가지로 정상 발성군과 기식적인 발성개시군, 강한 성대접촉 발성개시군과 기식적인 발성 개시군 간에 유의한 차이를 보였으며 이러한 결과는 MinArea의 결과를 뒷바침할 수 있다. MaxOpen 측정치는 발성 개시 유형 간에 는 유의한 차이는 없었으나, 남성이 여성에 비해 유의하게 넓게 관 

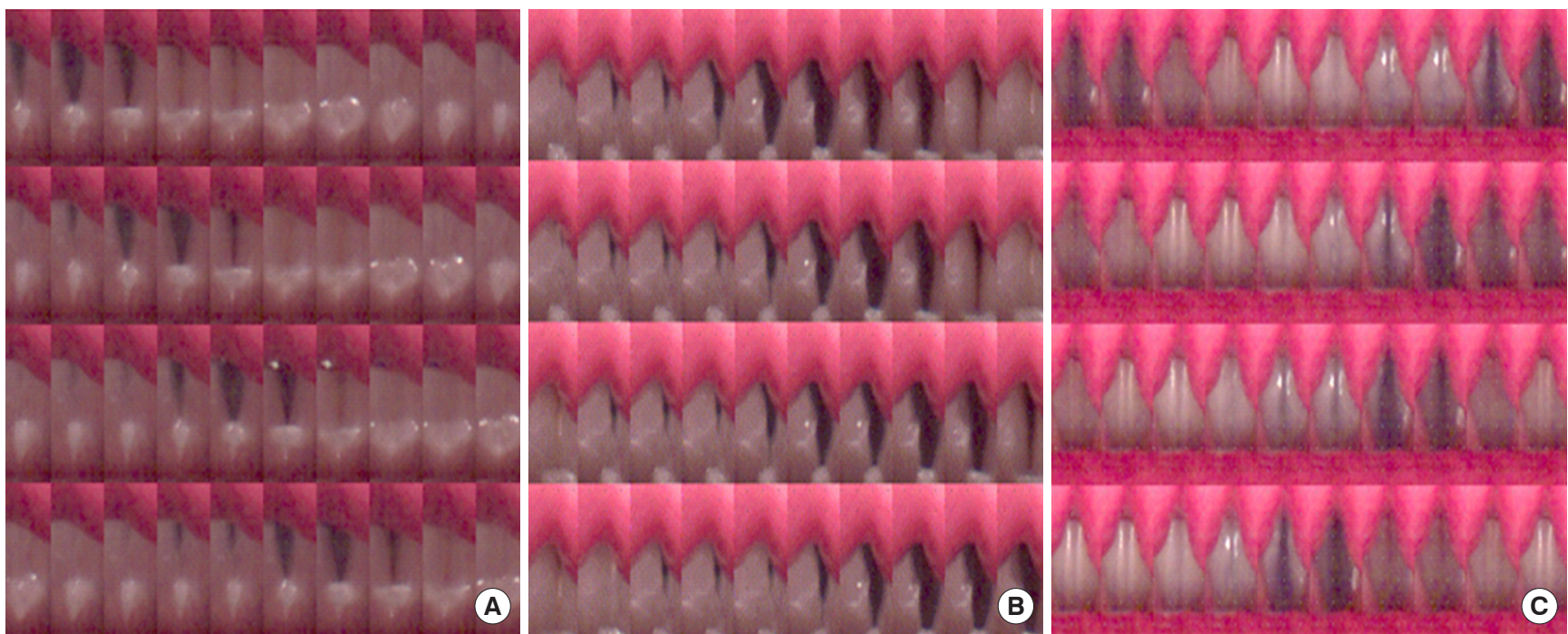

Figure 8. Montage of vocal fold vibration according to normal (A), breathy (B), and hard glottal attack onset (C).

찰되었다. 이는 발성 동안 남성이 여성에 비해 성문의 중간지점에서 최대개방너비가 넓은 것을 의미하는 데 MaxOpen에 차이를 보이 는 것은 남성과 여성의 $\mathrm{f} 0$ 의 차이로 여겨진다. 본 연구에서 남성과 여성은 각각 편안한 음도와 강도에서 소리를 내도록 유도하였기 때 문에 두 군 간에 기본주파수에 차이가 있다. Yamauchi 등(2015)의 정상 화자의 연령과 성별에 따른 VKG 연구에 의하면, 성대진폭은 $\mathrm{f} 0$ 와 유의한 부적인 상관성을 보였으며, 공기역학적인 변수들과는 약한 상관성을 나타내었고, 여성은 남성에 비해 높은 f0와 유의하 게 낮은 진폭을 보여 본 연구의 결과와 일치하였다.

$\mathrm{SQ}$ 측정치를 비교하였을 때 기식적인 발성개시>정상 발성개시 $>$ 강한 성대접촉 발성개시 순이었으며 기식적인 발성 개시가 유의 하게 높았고, 남성이 여성에 비해 유의하게 높았다. 강한 성대접촉 발성개시군의 경우 강한 힘으로 성문 접촉을 하였음에도 가장 느린 $\mathrm{SQ}$ 를 보여주었는데, 이러한 결과는 강한 성문접촉 발성이 좀 더 강 한 폐쇄를 보임에도 불구하고 성대내전속도가 정상 발성이나 기식 적인 발성 개시로 시작했을 때보다 느림을 의미하는 것으로 이는 근 육의 긴장에 의한 억압성이나 노력성 발성이 베르누이 효과에 의한 성대내전에 비해 덜 효과적임을 알 수 있다. Cooke 등(1997)의 연구 결과에서 기식적인 발성 시작이 강한 성문접촉 발성보다 성문개방 시간이 더 길다고 하였으며, Wittenberg 등(1995)의 연구에서도 강 한 성대접촉 발성개시군이 기식적인 발성개시군이나 정상 발성보 다 느린 내전 속도를 보였으며 기식적인 발성 개시 시에 후성문틈이 두드러지게 발견되어 본 연구결과와 유사한 결과를 나타내었다.

본 연구에서는 성별에 따라 $\mathrm{CQ}$ 와 $\mathrm{OQ}$ 는 차이를 보이지 않았으 나, 발성 개시 유형에 따라 $\mathrm{OQ}$ 와 $\mathrm{CQ}$ 간 유의한 차이가 있었는데,
$\mathrm{OQ}$ 는 기식적인 발성, 정상 발성, 강한 성대접촉 순으로 높았으며, $\mathrm{CQ}$ 는 강한 성대접촉, 정상 발성, 기식적인 발성 순으로 높게 나타 났다. 이러한 결과는 강한 성대접촉은 성대가 완전히 폐쇄되므로 폐쇄지수가 높게 나타나고, 기식적인 발성은 적은 힘으로 성대를 완전히 폐쇄하지 않고 발성하기 때문에 개방지수가 높게 나타난 것 으로 볼수 있다.

Woo (1996)는 정상 성인 남성 32명과 여성 33명을 대상으로 후 두비디오스트로보스코피 영상을 사용하여 GAW를 분석하여 남 성과 여성의 성대진동 특성을 분석하였다. 또한, Noordzij와 Woo (2000)는 후두비디오스크로보스코피 영상을 통해 24명 양성성대 병변 환자를 대상으로 후두미세수술 전후 GAW 분석을 실시하였 으며, 수술 후 최대성문공간면적과 최대폐쇄율 및 개방률이 증가 하여 수술 후 성대진동의 기능이 개선되었음을 보고하였으며, 성대 유연성(pliability)의 객관적 지표로서 임상적으로 매우 유용함을 시사하였다. 한편, Yamauchi 등(2016)은 초고속 디지털 후두내시 경을 사용하여 성대반흔 환자의 성대 움직임을 카이모그래프와 $\mathrm{GAW}$ 분석을 통해 객관적이고 정량적으로 성대진동을 분석하였 는데, 성대반흔 환자들이 정상대조군에 비해 더 긴 개방지수와 더 큰 성문최소면적을 나타낸다고 하였다.

DKG 분석결과, 발성 개시의 유형은 발성 개시 후 성대의 안정적 인 발성 부분에 영향을 주었는데, 강한 성대접촉은 안정된 발성 구 간에서도 유의하게 $\mathrm{CQ}$ 가 가장 높았으며, 가장 낮은 개방기를 보였 다. 반면, 기식성 발성 개시는 안정된 구간에서도 폐쇄기보다 개방 기가 더 긴 형태의 발성 패턴을 보였는데 이러한 특성은 발성 개시 가 안정된 구간의 성대진동에도 영향을 주어 전반적인 음질에 영 
향을 줌을 알 수 있다.

결론적으로, 본 연구는 초고속디지털카메라와 평면 스캔 비디오 카이모그래피, 디지털 카이모그래피를 동시에 측정하여 발성 개시 이전 및 성대 개시 부분과 성대의 안정된 구간의 진동을 다기능적 으로 살펴 보았다. 발성 개시 부분은 발성의 부분에서 가장 임상적 으로 중요한 정보를 제공하며 과기능 및 과소기능 음성장애의 병 리적 원인 및 성대진동 메커니즘을 이해하는 데 도움을 준다. 본 연 구의 결과를 토대로 음성장애 환자의 음성을 평가하고 치료할 때 발성 개시 특성이 발성의 안정된 부분에도 영향을 주므로 발성 개 시의 진동 특성을 잘 평가하고 이해하는 것은 음성장애를 감별하 고 치료하는 데 매우 중요한 정보를 제공할 것이다. 본 연구는 많은 수의 정상 화자를 포함하지 못하였으나 성별과 발성 개시 유형에 따른 성대 기능을 평가하기 위한 기초자료로 사용될 수 있을 것이 다. 추후의 연구에서는 다양한 연령과 환자군을 포함하여 발성 개 시의 특성을 살펴보는 것이 필요하며 다양한 $\mathrm{DKG}$ 측정치와 음질 간의 상관성을 살펴 봄으로써 음질에 기여하는 객관적인 성대진동 측정치를 찾아낼 수 있을 것이다.

\section{REFERENCES}

Andrade, D. F., Heuer, R., Hockstein, N. E., Castro, E., Spiegel, J. R., \& Sataloff, R. T. (2000). The frequency of hard glottal attacks in patients with muscle tension dysphonia, unilateral benign masses and bilateral benign masses. Journal of Voice, 14(2), 240-246.

Chen, W., Woo, P., \& Murry, T. (2018). Vibratory onset of adductor spasmodic dysphonia and muscle tension dysphonia: a high-speed video study. Journal of Voice. https://doi.org/10.1016/j.jvoice.2018.12.010

Choi, S. H., \& Choi, C. H. (2012). Qualitative analysis of vocal fold vibration in normal adults with a high-speed video system. Korean Journal of Communication \& Disorders, 17(4), 591-602.

Choi, S. H., Oh, C. S., \& Choi, C. H. (2015). Pattern Analysis of Voice Onset and Offset in Normal Adults Using High-Speed Digital Imaging: The Role of Arytenoid Cartilage Movements. Communication Sciences \& Disorders,20(4),607-616.

Cooke, A., Ludlow, C. L., Hallett, N., \& Selbie, W. S. (1997). Characteristics of vocal fold adduction related to voice onset. Journal of Voice, 11(1), 12-22.

Deliyski, D. D., Petrushev, P. P., Bonilha, H. S., Gerlach, T. T., Martin-Harris, B., \& Hillman, R. E. (2008). Clinical implementation of laryngeal highspeed videoendoscopy: challenges and evolution. Folia Phoniatrica et Logopaedica, 60(1), 33-44.
Iwahashi, T., Ogawa, M., Hosokawa, K., Kato, C., \& Inohara, H. (2017). The effects of humming on the prephonatory vocal fold motions under highspeed digital imaging in nondysphonic speakers. Journal of Voice, 31(3), 291-299.

Kang, D. H., Wang, S. G., Park, H. J., Lee, J. C., Jeon, G. R., Choi, I. S., ... \& Shin, B. J. (2017). Real-time simultaneous DKG and 2D DKG using highspeed digital camera. Journal of Voice, 31(2), 247.e1-247.e7.

Kim, G. (2017). The efficacy of simultaneous visualization modality for vocal fold vibration: laryngeal videoendoscopy and 2D scanning videokymography (Doctoral dissertation). Pusan National University, Busan, Korea.

Koike, Y., Hirano, M., \& Von Leden, H. (1967). Vocal initiation: acoustic and aerodynamic investigations of normal subjects. Folia Phoniatr (Basel), 19(3), 173-182.

Noordzij, J. P., \& Woo, P. (2000). Glottal area waveform analysis of benign vocal fold lesions before and after surgery. Annals of Otology, Rhinology \& Laryngology, 109(5), 441-446.

Orlikoff, R. F., Deliyski, D. D., Baken, R. J., \& Watson, B. C. (2009). Validation of a glottographic measure of vocal attack. Journal of Voice, 23(2), 164-168.

Patel, R., Dailey, S., \& Bless, D. (2008). Comparison of high-speed digital imaging with stroboscopy for laryngeal imaging of glottal disorders. Annals of Otology, Rhinology \& Laryngology, 117(6), 413-424.

Patel, R. R., Dixon, A., Richmond, A., \& Donohue, K. D. (2012). Pediatric high speed digital imaging of vocal fold vibration: a normative pilot study of glottal closure and phase closure characteristics. International Journal of Pediatric Otorhinolaryngology, 76(7), 954-959.

Švec, J. G., \& Schutte, H. K. (1996). Videokymography: high-speed line scanning of vocal fold vibration. Journal of Voice, 10(2), 201-205.

Švec, J. G., Šram, F., \& Schutte, H. K. (2007). Videokymography in voice disorders: what to look for? Annals of Otology, Rhinology \& Laryngology, 116(3), 172-180.

Tigges, M., Wittenberg, T., Mergell, P., \& Eysholdt, U. (1999). Imaging of vocal fold vibration by digital multi-plane kymography. Computerized Medical Imaging and Graphics, 23(6), 323-330.

Titze, I. R. (2000). Principles of voice production. Iowa City, IA: National Center for Voice and Speech.

Wang, S. G., Park, H. J., Cho, J. K., Jang, J. Y., Lee, W. Y., Lee, B. J., ... \& Cha, W. (2016a). The first application of the two-dimensional scanning videokymography in excised canine larynx model. Journal of Voice, 30(1), 1-4.

Wang, S. G., Park, H. J., Lee, B. J., Lee, S. M., Ko, B., Lee, S. M., \& Park, Y. M. (2016b). A new videokymography system for evaluation of the vibration 
pattern of entire vocal folds. Auris Nasus Larynx, 43(3), 315-321.

Watson, B. C., Baken, R. J., \& Roark, R. M. (2016). Effect of voice onset type on vocal attack time. Journal of Voice, 30(1), 11-14.

Werner-Kukuk, E., \& von Leden, H. (1970). Vocal initiation: high speed cinematographic studies on normal subjects. Folia Phoniatrica (Basel), 22(2), 107-116.

Wittenberg, T., Moser, M., Tigges, M., \& Eysholdt, U. (1995). Recording, processing, and analysis of digital high-speed sequences in glottography. $M a-$ chine Vision and Applications, 8(6), 399-404.

Wittenberg, T., Tigges, M., Mergell, P., \& Eysholdt, U. (2000). Functional imaging of vocal fold vibration: digital multislice high-speed kymography.
Journal of Voice, 14(3), 422-442.

Woo, P. (1996). Quantification of videostrobolaryngoscopic findings-measurements of the normal glottal cycle. Laryngoscope, 106(3), 1-27.

Yamauchi, A., Yokonishi, H., Imagawa, H., Sakakibara, K. I., Nito, T., Tayama, N., \& Yamasoba, T. (2016). Quantification of vocal fold vibration in various laryngeal disorders using high-speed digital imaging. Journal of Voice, 30(2), 205-214.

Yamauchi, A., Yokonishi, H., Imagawa, H., Sakakibara, K. I., Nito, T., Tayama, N., \& Yamasoba, T. (2015). Quantitative analysis of digital videokymography: a preliminary study on age-and gender-related difference of vocal fold vibration in normal speakers. Journal of Voice, 29(1), 109-119. 


\section{국문초록}

\section{평면 스캔 카이모그래피와 초고속 비디오 후두경검사를 이용한 정상화자의 발성유형에 따른 발성 개시 및 성대 진동 특성}

최성희 ${ }^{1,2} \cdot$ 주민식 ${ }^{3} \cdot$ 채혜림 $^{3} \cdot$ 최철희 ${ }^{1,2}$

${ }^{1}$ 대구가톨릭대학교 바이오메디대학 언어청각치료학과, ${ }^{2}$ 생체모방감각제어연구소 및 가톨릭 청각음성언어센터, ${ }^{3}$ 대구가톨릭대학교 일반대학원 언어청각치료학과

배경 및 목적: 발성 개시는 병리학적 음성을 진단하는 데 중요한 임상적 단서를 제공한다. 본 연구의 목적은 카이모그래피와 초고속 디 지털 영상을 사용하여 발성 유형(정상, 기식적인, 강한 성대접촉)에 따른 발성 개시 특성을 조사하였다. 이외에 발성 개시가 음성의 안정 된 부분의 성대진동에 어떠한 영향을 미치는 지 살펴 보기 위하여 안정된 구간의 발성을 정량적으로 분석하였다. 방법: 35 명의 정상 청 년층을 통해 서로 다른 발성 개시 유형(정상, 기식성 혹은 부드러운 발성, 강한 성대접촉)에 따라 초고속 디지털 영상을 얻어내었다. 발성 전과 발성 개시 데이터는 $\mathrm{DKG}$ 를 이용하여 질적으로 분석하였으며, 안정된 발성 구간은 MinArea, MaxArea, MinOpen, MaxOpen, $\mathrm{SQ}$ 는 성문공간파형 $(\mathrm{GAW})$ 분석을 이용하여 정량적으로 분석하였으며, $\mathrm{CQ}$ 및 $\mathrm{OQ}$ 는 다기능 후두성능검사시스템의 $2 \mathrm{D} \mathrm{DKG}$ 를 사용 하여 분석하였다. 결과: MinArea는 기식적인 발성에서 통계학적으로 유의하게 높았으며( $p$ <.001), 성별 차이는 없었다. MaxArea는 성

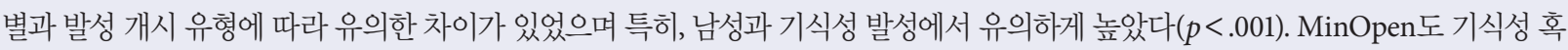
은 부드러운 발성에서 유의하게 넓었다. MaxOpen은 발성 유형 간에는 유의한 차이가 없었으며, 남성에서 유의하게 넓게 나타났다. 또 한, $\mathrm{SQ}$ 는 기식성 발성에서 유의하게 높았으며, $\mathrm{OQ}$ 와 $\mathrm{CQ}$ 는 성별 차이는 유의하지 않았으나, 발성 유형에 따라 유의한 차이를 보였다 $(p<.001)$. 논의 및 결론: $\mathrm{HSDI}$ 와 $\mathrm{DKG}$ 는 발성 개시를 관찰하는 데 용이 하였으며, 발성 개시 유형에 따라 발성 전과 발성 개시에서 뚜 렷한 차이를 보였다. 또한 발성 개시 동작은 안정된 발성 구간에서 성대진동에도 영향을 주었다.

핵심어: 발성 개시, 성문공간파형 분석, 초고속 디지털 영상, 평면 스캔 카이모그래피, 발성 유형

본 연구는 대구가톨릭대학교 2019년도 교내 연구비 지원을 받아수행되었음.

\section{참고문헌}

김근효(2017). 후두내시경 검사와 평면 스캔 비디오카이모그래피 동시 측정의 효과. 부산대학교 대학원 박사학위논문. 최성희, 최철희(2012). 초고속성대촬영시스템을 이용한 정상 성인 성대 움직임의 질적 분석. 언어청각장애연구, 17(4), 591-602.

최성희, 오치선, 최철희(2015). 초고속 성대촬영 이미지를 이용한 정상 성인의 발성개시와 종료에 대한 패턴 분석: 피열연골 움직임의 역할. 언어청각장 애연구, 20(4), 607-616.

\section{ORCID}

최성희(제1저자, https://orcid.org/0000-0003-2365-6187); 주민식(공동저자, https://orcid.org/0000-0002-8087-7261); 채혜림(공동저자, https://orcid.org/0000-0002-9088-5425); 최철희(교신저자, https://orcid.org/0000-0003-1844-3072) 